\title{
A AGONIA DO NARRADOR EM A PASSAGEM TENSA DOS CORPOS
}

Jorge Amaral ${ }^{1}$

\section{RESUMO}

$O$ artigo analisa a figura do narrador do romance $A$ passagem Tensa dos corpos (2009), de Carlos de Brito e Mello, a partir de reflexões sobre o Pós-modernismo e o Pós-Pós-Modernismo. Inicialmente, analisa-se o processo de "desterritorialização" do sujeito pós-moderno do final do século $X X$, tanto no sentido de pertencimento local quanto no sentido estético. A partir daí investiga-se o surgimento, no início do século XXI, do chamado Pós-Pós-Modernismo como um momento de resgate das categorias literárias. Diante dessas reflexões, o artigo mergulha na análise da inusitada configuração do narrador do romance de Brito e Mello, que tem por característica essencial o fato de ser um organismo sem forma, ou seja, um ser inteiramente textual, linguístico, cuja movimentação está necessariamente ligada à movimentação do texto.

Palavras-chave: Narrador. Pós-modernismo. Pós-Pós-modernismo. Desterritorialização. Carlos de Brito e Mello.

THE AGONY OF THE NARRATOR IN A PASSAGEM TENSA DOS CORPOS

\begin{abstract}
The article analyzes the figure of the narrator of the novel A Passagem Tensa dos Corpos (2009), by Carlos de Brito e Mello, from reflections about Postmodernism and Post-Postmodernism. Initially, we analyze the process of "deterritorialization" of the postmodern subject of the late twentieth century, both in the sense of local belonging and in the aesthetic sense. From then investigates the emergence, in the early
\end{abstract}


twenty-first century, the so-called Post-Postmodernism as a moment of redemption of literary categories. Given these considerations, the article delves into the analysis of the unusual configuration of the narrator of the novel Brito e Mello, whose essential characteristic is being a body without form, that is, a wholly textual being, a wholly linguistic being, whose movement is necessarily linked to the movement of the text.

Keywords: Narrator. Postmodernism. Post-Postmodernism. Deterritorialization. Carlos de Brito e Mello.

\section{INTRODUÇÃO}

O atual cenário da produção literária nacional encontra-se em um momento de confluência de diferentes tendências. Até o fim da década de 1990, de uma forma geral, a literatura brasileira estava mergulhada em uma realidade construtiva que dispensava o direcionamento a categorias estéticas específicas, pois já não havia espaço para a valorização da unidade. É a literatura Pós-moderna. O narrador pósmoderno é, antes de tudo, um observador, que recorre à realidade externa e a transforma em matéria literária. E esse objeto de observação é um mundo sem cara definida, sinuoso e fragmentado, e o narrador, como produtor do retrato desse mundo pode também acabar se fragmentando. E então, fragmentado, não há como se direcionar de forma coesa, a ponto de se enquadrar em um organismo de classificação literária. Isso faz com que a literatura pós-moderna seja desterritorializada em seu próprio princípio de realização, o que resulta em uma produção imprecisa até como arte literária. Assim, podemos encontrar romances que dialogam com roteiros cinematográficos, romances com dinâmicas jornalísticas ou até com uma concisão emprestada das maneiras modernas de construção poética.

Sem que esse cenário tenha totalmente se dissipado, começa a surgir, sobretudo a partir da primeira década do século XXI, uma literatura que procura se reconciliar com uma possível linha evolutiva da literatura brasileira. É o chamado Pós-Pós-modernismo. Essa tendência à reconciliação pode muito bem ser confundida com uma postura retrógrada, que busca a legitimização por intermédio da autoridade literária estabelecida ainda na virada do século XIX para o XX, ainda no período pré-moderno. No entanto, o que se percebe nessa nova tendência é um 
resgate das categorias literárias, sobretudo no sentido de se recuperar os mecanismos de produção que estejam direcionados às formas de construções literárias específicas do universo do romance. Ou seja, um romance compromissado, sobretudo, com sua própria realidade construtiva. Neste sentido, ao resgatar a autonomia do texto literário, esse novo romance fortalece as fronteiras estéticas, redimensiona a unidade perdida do texto, abre novos horizontes para reenquadramento das artes literárias dentro de realidade diacrônica da linha evolutiva da literatura romanesca do país.

Assim, a linguagem crua como reflexo da realidade cotidiana passa a dar lugar a um texto mais preocupado com sua própria realidade enquanto arte literária. Ou seja, se esse texto dita um acontecimento lotado de violência, não será essa violência que irá ditar o ritmo do texto, mas, antes, será o texto que moldará a forma com que essa violência será retratada. E o texto, então, volta para o centro das atenções, sobretudo por conta do fenômeno da reestruturação de sua unidade. E nesse cenário de combate entre as forças de fragmentação e de anseio pela recuperação da unidade surge $A$ passagem tensa dos corpos.

Desta forma, poderemos perceber que, aqui, os esforços se concentrarão na análise do objeto literário a partir de sua própria realidade estética. A partir de seus princípios particulares de concepção. Não haverá, então, uma preocupação em enquadrar o romance em uma ou outra tendência literária. Na verdade, este breve estudo buscará penetrar nos meandros narrativos do romance no sentido de, na medida do possível, tentar elucidar ao máximo as singularidades do seu processo constitutivo. E isso, é claro, acabará fazendo com que o livro, em alguns momentos, tenha afinidades com alguns segmentos literários. No entanto, poderemos perceber que o caráter inusitado da construção $A$ Passagem tensa dos corpos é tão significativo, que a tentativa de um total enquadramento em pressupostos estéticos específicos poderá não dar conta do que o romance realmente representa.

\section{A TENSA PASSAGEM DO NARRADOR}

Surgido a partir da contemplação do prêmio Governo de Minas Gerais de Literatura, na categoria Escritor Mineiro, no ano de 2008, A passagem tensa dos corpos, de Carlos de Brito e Mello, foi escrito em aproximadamente seis meses, e publicado no ano seguinte, 2009. Sua chegada no cenário literário brasileiro não 
passou em branco. O livro foi finalista do prêmio Portugal Telecom de 2010, do prêmio São Paulo de Literatura do mesmo ano, na categoria estreante, e do Jabuti, na categoria romance.

Sua receptividade por parte da crítica também foi bastante positiva. $O$ crítico e ensaísta José Castello, por exemplo, dedicou a ele seu voto para o prêmio Portugal Telecom:

Mas $A$ passagem tensa dos corpos me derrubou. Nunca li nada parecido. Poucos escritores, como Carlos, um jovem professor de 35 anos que só na noite da premiação vim a conhecer, chegam a enfrentar, com tanto destemor, os limites frágeis, quase inúteis, da linguagem. O livro tem defeitos, sim. Não disfarça o que é: um romance de estreia. Mas com que coragem! $!^{2}$

O livro, é bom que se diga, trata da morte, um assunto de extremo apelo emocional, mas com um significativo esmero técnico em seu aspecto construtivo. A morte, que de uma forma geral representa o fim de um ciclo existencial para os indivíduos, para o narrador de $A$ passagem, é a suprema continuação da existência. Ela é mola-mestra do romance, e é em torno dela que tudo irá se desenvolver. No entanto, toda essa força da plenitude da morte está representada por uma estrutura textual extremamente técnica. Nada no texto está ali por capricho gráfico e estilístico. Tudo aparecerá como representação da realidade existencial do narrador. Na verdade, a morte, mais do que representar o fim, o início ou a continuação de algo, será a verdadeira representação da incompletude, da fragmentação e da onipresença do narrador. Mas isso só se torna nítido quando se percebem as formas de configuração desse narrador e sua relação íntima com a estrutura textual e até mesmo gráfica do romance.

Neste sentido, o texto encontra nas diversas formas de caracterizar a morte o seu grande veículo de desenvolvimento. O narrador é um estranho, um ser sem forma, que tem como ofício o registro de mortes. Ele atravessa todo o estado de Minas Gerais registrando todo o tipo de falecimento e nisso se resume o cerne de sua realidade existencial. No entanto, para continuar com seu inusitado ofício, ele precisa que sejam cumpridos os rituais fúnebres do morto. Em um determinado momento, porém, ele encontra um homem que ele passa a chamar de C., que aparentemente fora morto por envenenamento, e que está preso e esquecido em um quarto. A família estranhamente não cumpre os rituais fúnebres e ignora a presença 
do morto, o que impede que o narrador continue sua caminhada rumo ao registro de outras mortes.

Essa família, por sua vez, tem uma configuração não menos inusitada. A dona da casa ignora a figura do morto, esquecido em um dos cômodos; a mais velha dos dois filhos passa todo seu tempo se preparando para um casamento sem a existência do noivo; e o filho mais novo está todo o tempo dentro do quarto sem que haja nenhum motivo concreto que o prenda lá. E é em meio a esse conturbado cenário familiar, e ao contínuo registro de mortes que grande parte do romance se desenvolve.

Em princípio, esse quadro poderia pressupor uma série de acontecimentos macabros e violentos, ou seja, um prato cheio para as pretensões pós-modernas. No entanto, essa atmosfera mórbida acaba sendo dissipada pela própria forma com que o narrador encara seu ofício. Neste sentido, é importante que nos detenhamos na configuração desse narrador e na forma com que ele se manifesta no desenvolvimento da trama.

No romance de Carlos de Brito e Mello, o narrador é um ser de inusitada configuração. Ele é essencialmente um ser linguístico. Ele é o próprio texto que se desenvolve.

Toda nota necrológica refere-se, direta ou indiretamente, a um elemento de minha serventia. Sou um excluído que produz um discurso. A palavra é o único indício de minha presença, e é só por meio dela que toda ação e toda a matéria podem aqui se realizar. (MELLO, 2004, p. 116).

No entanto, esse estranho indivíduo verbal, como não tem forma, acaba encarnando tudo aquilo que ele tenta retratar, uma vez que ele é a encarnação da própria matéria narrativa. Assim, quando relata uma série de mortes em uma determinada cidade, pelo fato de esse relato ser estritamente de natureza vocabular, esses relatos acabam se configurando na própria realidade existencial do narrador. Ele é aquilo que relata. Um ser constituído de matéria literária, mas que está em uma constante busca da liberdade das grades gramaticais. E isso ele só conseguirá quando se reintegrar como ser orgânico, físico, material. Um ser humano. Mas enquanto isso não ocorre, ele segue abstrato em sua composição orgânica, mas extremamente concreto em seus anseios existenciais. Então, mesmo não existindo como matéria, ele existe como conjunto de sensações. Por isso, ele é um narrador 
crítico, emocional e que está sempre emitindo opiniões acerca das questões relacionadas à vida contemporânea. $\mathrm{E}$ com $\mathrm{o}$ decorrer da narrativa, esse estranho narrador vai se mostrando, ou seja, à medida que o romance vai se desenvolvendo, ele, como ser linguístico vai se tornando mais nítido ao leitor. Por isso, já na segunda metade do livro, percebe-se que esse narrador, em algum momento, teve uma vida convencional. Como se pressupõe por esparsas indicações, ele, quando menino, foi acusado de atentar contra a vida de sua babá e, por isso, foi asfixiado e morto por sua própria mãe. Ora, como, em princípio, nota-se que estamos diante de um narrador adulto, pressupõe-se que ele amadurecera apenas verbalmente, e não como ser humano, e por isso ele estaria em busca de sua completude.

Mas é importante que se diga que esse narrador fragmentado não é o mesmo narrador fragmentado do pós-modernismo. O que temos aqui é um narrador incompleto em uma busca desenfreada pela completude. A fragmentação, aqui, é o triste retrato de sua própria realidade existencial. E ele, como indivíduo linguístico incompleto, apresenta-se na página envolvido também por essa atmosfera desprovida de totalidade, e isso explica o fato de o texto ter uma disposição gráfica também pouco convencional, que exala um forte teor de conturbação gráfica, que também pode representar a aparência do narrador, como afirma o próprio autor:

Em parte, A passagem tensa dos corpos procurou mostrar essa
relação que a palavra estabelece com o seu próprio
desaparecimento, e o fez por meio de um conjunto de mortes - de
desaparecimentos, portanto - que se tornaram condição para a
almejada existência material do narrador. Os cortes nas frases, a
estruturação dos parágrafos em blocos e a fragmentação dos
capítulos tornaram-se, por sua vez, formas pelas quais a perda, a
quebra e a falta puderam se manifestar na narrativa. ${ }^{3}$

Dessa forma, a fragmentação e a incompletude, tão valorizadas pelo pósmodernismo, aqui se apresentam como um estado do qual o narrador tenta a todo o tempo escapar, mas que faz parte de sua realidade existencial. A disposição gráfica aparentemente gratuita do texto e os parágrafos curtos denunciam, além de um constante estado desconfortável de fragmentação, um estado de conturbação existencial do próprio narrador. No entanto, o texto não lança mão de recursos linguísticos ásperos e aleatórios. A linguagem utilizada é extremamente elaborada, o que demonstra um narrador errante entre os intuitos estéticos de elaboração da linguagem e as limitações gráficas oriundas de seu próprio estágio existencial. 
E como não possui matéria significativa, poderia se pressupor que o narrador também estivesse livre das amarras espaciais do compromisso. Esperava-se, em princípio, um narrador, por ser desmaterializado, também desterritorializado. Mas, curiosamente, percebe-se um ser com as raízes profundamente vinculadas às terras de Minas Gerais, uma vez que todas as mortes relatadas são ocorridas apenas nas cidades do interior mineiro.

Neste sentido, poderíamos supor que $A$ passagem tensa dos corpos é um romance que, se ainda não está inserido na gama produtiva emergida após as correntes pós-modernas, por conta de um estranho estágio existencial do narrador, talvez também não se vincule tão confortavelmente na tendência chamada de PósPós. Ora, se uma das características da narrativa pós-moderna é a fragmentação e o narrador do romance Carlos de Brito e Mello é a própria encarnação do sujeito despedaçado, essa incompletude é a própria razão da agonia do narrador, e não uma simples opção existencial e estética. Além disso, a constante presença equivocada do narrador nas cidades, como uma espécie de onipresença resultante de uma errância constante, não denuncia uma desterritorialização, já que seu campo de atuação resume-se exclusivamente ao estado de Minas Gerais.

Por outro lado, esse estágio existencial do narrador como indivíduo vocabular empresta ao texto características que talvez o afastem da tendência Pós-Pós. Mesmo sendo um sujeito extremamente territorializado, ele é um organismo em constante movimento, o que acaba acarretando uma narrativa rápida, de capítulos curtos, e de disposição gráfica difusa. Aqui não há espaço para constantes convenções gráficas, como travessões e inícios de parágrafos com letras maiúsculas, por exemplo. O texto passa a impressão de que a agonia do narrador na busca de sua completude é o anseio pelo convencionalismo textual, como um ser com uma doença crônica e degenerativa, mas que não desiste de sua constante busca pela cura. Um ser que busca, mas não consegue mudar suas características. E a prova disso é que, no fim do livro, quando ele finalmente encontra completude material, com a apropriação de C. - o morto a quem ele se vincula -, o romance encontra o seu fim.

Tantas vezes acompanhei com irritação a mastigação alheia e só agora percebo que meu banquete esteve sempre servido. Devo me dedicar, pois, ao consumo de toda a química que convém a quem precisa constituir para si um corpo inteiro e vivo.[...]

C. de carbono, C. de corpo [...] 
C. de cadáver. Começo por lamber o seu rosto putrescente e, com ele, ocupo toda a extensão da minha língua. Nela não cabe mais a palavra. (BRITO, 2004, p. 249).

E se não cabe mais a palavra, o narrador volta a existir como matéria humana e deixa de existir apenas como realidade vocabular. É o fim do romance.

\section{CONSIDERAÇÕES FINAIS}

Como se pode perceber, A passagem tensa dos corpos é um livro de características bem peculiares, já que narrador (um ser exclusivamente linguístico), narrativa e objeto narrado encontram-se em um íntimo diálogo construtivo, que influenciam até mesmo a realidade gráfica do texto. O romance transita por caminhos sinuosos, que apontam tanto para o universo pós-moderno (denunciado pela velocidade narrativa e pela fragmentação do texto - até mesmo em seu aspecto visual - e do narrador), como para uma tendência denominada Pós-Pós, uma vez que se percebe o esmero na manipulação da linguagem e no total direcionamento da suprema autonomia do texto.

Da mesma forma, seria arriscado enquadrá-lo nos gêneros irrealistas, mesmo tendo como narrador uma espécie de ser espectral e onipresente, sobretudo pelo fato de o narrador apresentar-se como um morto que diz ser, em sua essência, um indivíduo formado estranhamente por fonemas.

Eu sou uma forma possível para a perda. E a violência que origina toda nomeação em minha infância, abateu-se sobre o conjunto de fonemas organizados para designar-me meu nome também não se pronuncia. (BRITO, 2004, p. 53).

Ele não pretende ser outra coisa enquanto o romance se desenvolve (note-se que quando se apodera do corpo de C. ele deixa de ser exclusivamente texto, volta a ser humano, e o romance acaba.). Ou seja, enquanto há o romance, há o texto, e enquanto há o texto, há um narrador assumindo sua condição de indivíduo unicamente vocabular. Neste sentido, pode-se dizer que tudo o que poderia esbarrar nos irrealismos acaba freado por justificativas metalinguísticas que dão autenticidade à própria realidade do texto.

Este é um romance extremamente veloz, de concepção inusitada e cuja totalidade encontra-se exatamente na incompletude de sua concepção. Ele não é 
um livro de respostas nem de conclusões, e é exatamente aí que repousa sua realidade. No decorrer do texto, sob uma atmosfera extremamente perturbadora, leitor e narrador compartilham de uma agonia comum. No caso do narrador, a angústia pela busca da completude, por parte do leitor, a agonia pela recepção dela. No entanto, ao final do texto, a parceria esbarra em seu limite. O narrador encontra seu corpo, completa-se, e, por fim, deixa de ser texto, restando apenas ao leitor a sensação agonizante da incompletude da compreensão da mensagem.

\section{NOTAS}

1 Bolsista do CNPq, é graduado, mestre e doutorando em Literatura Brasileira (UFRJ). Atua também na área editorial como parecerista da editora Record, e revisor da Editora Ediouro e CEDERJ.

${ }^{2}$ Texto do crítico José Castello, publicado no endereço:

http://oglobo.globo.com/blogs/literatura/posts/2010/11/12/o-devorador-de-livros-340540.asp, sobre $A$ passagem tensa dos corpos na ocasião da indicação do livro para o prêmio Portugal Telecom 2010. Acesso em 31 jul. 2011.

${ }^{3}$ Extraído de um texto do autor, no endereço: http://www.suplementopernambuco.com.br/index.php?option=com_content\&view=article\&id=108:jasem-mais-nem-menos-assim\&catid=2: bastidores\&ltemid=4, acerca do processo de produção de $A$ passagem tensa dos corpos. Acesso em 31 jul. 2011.

\section{REFERÊNCIAS}

CANDIDO, Antônio. A nova narrativa. In: ensaios. Rio de Janeiro: Ática, 1987. Educação pela noite e outros

CASTELLO, José. O devorador de livros. O Globo, [s. I.], nov. 2010. Disponível em: <http://oglobo.globo.com/blogs/literatura/posts/2010/11/12/o-devorador-de-livros340540.asp>. Acesso em: 31 jul. 2011

MELLO, Carlos de Brito e. A passagem tensa dos corpos. São Paulo: Companhia das Letras, 2009.

. Já, sem mais nem menos, assim. Suplemento Pernambuco, Recife, fev. 2010. Disponível em:

<http://www.suplementopernambuco.com.br/index.php?option=com_content\&view=a rticle\&id=108:ja-sem-mais-nem-menos-assim\&catid=2:bastidores\&ltemid=4>. Acesso em: 31 jul. 2011.

SANTIAGO, Silviano. O narrador pó-moderno. In: Nas malhas da letra. São Paulo: Companhia das Letras, [s. d.].

Teia literária: revista de estudos culturais - Brasil - Portugal - África. Jundiaí: In House, 2007. 